\title{
Genome wide screen identifies microsatellite markers associated with acute adverse effects following radiotherapy in cancer patients
}

\author{
Yuichi Michikawa', Tomo Suga', Atsuko Ishikawa', Hideki Hayashi², Akira Oka², Hidetoshi Inoko², \\ Mayumi Iwakawa', Takashi Imai ${ }^{1^{*}}$
}

\begin{abstract}
Background: The response of normal tissues in cancer patients undergoing radiotherapy varies, possibly due to genetic differences underlying variation in radiosensitivity.

Methods: Cancer patients $(n=360)$ were selected retrospectively from the RadGenomics project. Adverse effects within 3 months of radiotherapy completion were graded using the National Cancer Institute Common Toxicity Criteria; high grade group were grade 3 or more $(n=180)$, low grade group were grade 1 or less $(n=180)$. Pooled genomic DNA (gDNA) ( $n=90$ from each group) was screened using 23,244 microsatellites. Markers with different inter-group frequencies (Fisher exact test $P<0.05$ ) were analyzed using the remaining pooled gDNA. Silencing RNA treatment was performed in cultured normal human skin fibroblasts.
\end{abstract}

Results: Forty-seven markers had positive association values; including one in the SEMA3A promoter region ( $P=$ $1.24 \times 10^{-5}$ ). SEMA3A knockdown enhanced radiation resistance.

Conclusions: This study identified 47 putative radiosensitivity markers, and suggested a role for SEMA3A in radiosensitivity.

\section{Background}

A principle determinant of the efficiency of tumor eradication following radiotherapy is the total radiation dose given to a patient. The radiation tolerance of important organs located at the margins of the radiotherapy target volume is a critical issue in determining dose thresholds. However, variation in the genetic background of individuals also contributes to the severity of radiation-related adverse events [1-7].

Andreassen et al. have summarized the results of many genetic association studies that used single nucleotide polymorphisms (SNPs) as genetic markers, and compared allele frequencies in radiosensitive and nonradiosensitive individuals [7]. Most studies use a candidate gene approach; with genes selected based on ontology. In particular, these studies have focused on genes involved in

\footnotetext{
* Correspondence: imait@nirs.go.jp

${ }^{1}$ RadGenomics Project, Research Center for Charged Particle Therapy,

National Institute of Radiological Sciences, Chiba, Japan

Full list of author information is available at the end of the article
}

processes including response to DNA damage, cell death, cell cycle control, oxidative stress, radiation-induced fibrogenesis, and endothelial cell damage.

Systematic microarray gene expression analyses [8-13] and in vitro functional screening using siRNA knockdown of gene expression [14], have been used to identify potential radiation susceptibility genes. Significant association has been found between the risk of early adverse skin reactions (EASRs) following radiotherapy, and SNP haplotypes associated with six of 137 candidate genes (CD44, MAD2L2, PTTG1, RAD9A, LIG3 and REV3L) [15]. This has led to the development of a novel DNA chip-based technique to analyze haplotype markers in individual cancer patients [16-19].

Although positive associations between genetic markers and radiosensitivity have been found, the search for strongly associated genetic markers has been unrewarding [7], and this is partly due to inadequate understanding of the molecular pathology of adverse reactions induced by radiotherapy. 
Microsatellites are useful mapping tools as they are abundant and interspersed throughout the human genome, similar to SNPs. Importantly though, microsatellite polymorphism generally exceeds that of single SNPs, even reaching the degree of polymorphism provided by SNP haplotypes [20]. Thus, association analyses using a relatively small number of microsatellites should still have adequate statistical power relative to that provided by SNPs [20]. This is illustrated by the identification of genes associated with rheumatoid arthritis [21], narcolepsy [22] and Behcet's disease [23] using genome-wide association studies based on microsatellites.

Hence, a genome-wide association study was performed to identify candidate genes that are strongly associated with radiosensitivity in humans. The screen analyzed data from 23,244 microsatellites in 360 cancer patients who had undergone radiotherapy and been graded for normal tissue adverse reactions. Forty-seven markers were identified as being of interest, with a role for the involvement of $S E M A 3 A$ in radiosensitivity suggested.

\section{Methods}

\section{Grading of patients with low and high grade radiosensitivity}

Since 2001, the RadGenomics project has enrolled more than 3000 patients who have undergone radiotherapy. All patients provided written informed consent to participate in this study, which was approved by the Institutional Review Board at the National Institute of Radiological Sciences and by each collaborating institution. The acute adverse reactions of individual patients up to three months after completion of radiotherapy were graded according to the National Cancer Institute's Common Toxicity Criteria (NCICTC) version 2 . We retrospectively selected 180 patients, who presented with a severe acute reaction of equal to or greater than grade 3 , as a high-grade group (HGG). We also retrospectively selected 180 patients with less than or equal to grade 1 acute reaction on any end point, as a low-grade group (LGG). The assignment of patients to the LGG and HGG took into consideration their cancer type, age, gender, treatment type, and radiation dose (table 1).

\section{Preparation of pooled DNA samples}

Extraction of gDNA from whole blood was performed using an automatic nucleic acid isolator, NA3000S (Kurabo, Osaka, Japan) or with the QIAamp DNA blood kit (Qiagen, Hilden, Germany). The gDNA concentrations were measured in triplicate using a PicoGreen doublestranded DNA quantification kit (Invitrogen, Carlsbad, USA) and an SF600 microtiter plate reader (Corona Electric, Ibaraki, Japan). To reduce the amount of genotyping required, gDNA samples were pooled according to the method of Collins et al [24]. Concentrations of individual gDNA samples were adjusted to $8 \mathrm{ng} / \mu \mathrm{L}$. An equal volume of each of 90 gDNA samples from the HGG was combined to generate the first set of pooled gDNA and termed HGG-1. Similarly, 90 gDNA samples from the LGG were pooled and termed LGG-1. A second set of pooled gDNA samples was also prepared from 90 samples of the HGG and 90 samples of the LGG, and these were termed HGG-2 and LGG-2, respectively.

\section{Analysis of microsatellite markers}

All microsatellite markers and the methods for microsatellite analysis used in this study are described in Tamiya et al [21]. The genomic location of the microsatellite markers was investigated using the UCSC Genome Browser http://genome.ucsc.edu/cgi-bin/ hgGateway. PCR primers to amplify microsatellites were designed to anneal at $57^{\circ} \mathrm{C}$, with forward primers having a 5' fluorescent label (6-FAM or HEX). PCR was performed using the GeneAmp PCR system 9700 (GE Healthcare, Amersham Place, UK) in $20 \mu \mathrm{L}$ containing $48 \mathrm{ng}$ pooled DNA, $0.5 \mathrm{U}$ AmpliTaq DNA polymerase,

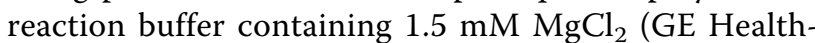
care, Amersham Place, UK), $5 \mu \mathrm{M}$ of each primer, and $0.25 \mathrm{mM}$ of each dNTP in 96- or 384-well plates. PCR profile was as follows; $96^{\circ} \mathrm{C}$ for $5 \mathrm{~min}, 57^{\circ} \mathrm{C}$ for $1 \mathrm{~min}$, $72^{\circ} \mathrm{C}$ for $1 \mathrm{~min} ; 40$ cycles of $96^{\circ} \mathrm{C}$ for $45 \mathrm{~s}, 57^{\circ} \mathrm{C}$ for $45 \mathrm{~s}$, $72^{\circ} \mathrm{C}$ for $1 \mathrm{~min}$. For microsatellite typing of individual samples, PCR was performed in $12 \mu \mathrm{L}$ containing $2 \mathrm{ng}$ DNA, 0.25 U AmpliTaq Gold DNA polymerase (GE Healthcare, Amersham Place, UK), reaction buffer containing $1.5 \mathrm{mM} \mathrm{MgCl}_{2}, 5 \mu \mathrm{M}$ of each primer, and 0.2 $\mathrm{mM}$ of each dNTP in 96- or 384-well plates and amplified as above. PCR products were denatured in $\mathrm{Hi}-\mathrm{Di}$ formamide (GE Healthcare, Amersham Place, UK) at $95^{\circ} \mathrm{C}$ for $3 \mathrm{~min}$ and separated by capillary electrophoresis using an ABI Prism 3700 Genetic Analyzer and ROX size standards (GE Healthcare, Amersham Place, UK). Analysis of fragment size and electrophoretograms was performed using GeneScan and Genotyper software (GE Healthcare, Little Chalfont, UK).

\section{Statistical analysis}

Allele frequencies in pooled DNA were estimated from the height of peaks in the electrophoretogram [21]. Association of microsatellites with radiosensitivity was assessed using Fisher exact test and $2 \times 2$ contingency tables for each allele. The lowest $P$ value for any allele of a particular microsatellite was used in analysis for that microsatellite marker and significance was set at 0.05 . To account for multiple testing across the microsatellite markers, the $P$ values of the second screening were adjusted using the false discovery rate (FDR) 
Table 1 Clinical features for patients in the genome screen

\begin{tabular}{|c|c|c|c|c|c|}
\hline \multirow[t]{2}{*}{ Characteristic } & \multicolumn{2}{|c|}{ initial genome screen } & \multicolumn{2}{|c|}{ focused screen } & \multirow[t]{2}{*}{ Difference between groups $(\mathrm{P})$} \\
\hline & $\begin{array}{c}\text { LGG-1 } \\
(n=90)\end{array}$ & $\begin{array}{l}\text { HGG-1 } \\
(n=90)\end{array}$ & $\begin{array}{c}\text { LGG-2 } \\
(n=90)\end{array}$ & $\begin{array}{l}\text { HGG-2 } \\
(n=90)\end{array}$ & \\
\hline \multicolumn{6}{|l|}{ Age at RT } \\
\hline Mean \pm SD & $59.7 \pm 14.6$ & $59.7 \pm 11.5$ & $62.5 \pm 12.8$ & $59.5 \pm 11.1$ & 0.434 \\
\hline Range & $26-89$ & $38-83$ & $38-88$ & $21-79$ & \\
\hline Family history of cancer & $33(36.7 \%)$ & $23(25.6 \%)$ & $42(46.7 \%)$ & $37(41.1 \%)$ & 0.129 \\
\hline \multicolumn{6}{|l|}{ Cancer type } \\
\hline Breast & 42 & 7 & 42 & 7 & \\
\hline Cervical & 15 & 27 & 15 & 27 & \\
\hline Esophageal & 4 & 15 & 4 & 15 & \\
\hline Head and neck & 10 & 30 & 9 & 31 & \\
\hline Lung & 18 & 10 & 19 & 9 & \\
\hline Prostate & 1 & 1 & 1 & 1 & \\
\hline
\end{tabular}

TNM classification

$\begin{array}{ccccc}\text { T1 } & 50 & 13 & 46 & 22 \\ \text { T2 } & 30 & 30 & 27 & 35 \\ \text { T3 } & 8 & 34 & 11 & 26 \\ \text { T4 } & 2 & 13 & 6 & 7 \\ & & & & \\ \text { N0 } & 72 & 43 & 72 & 40 \\ \text { N1 } & 12 & 30 & 13 & 27 \\ \text { N2 } & 6 & 10 & 4 & 17 \\ \text { N3 } & 0 & 6 & 1 & 5 \\ \text { N4 } & 0 & 0 & 0 & 1 \\ & & & & 81 \\ \text { M0 } & 90 & 78 & 87 & 9 \\ \text { M1 } & 0 & 12 & 3 & \end{array}$

Dose of radiotherapy $(\mathrm{Gy})^{*}$

$\begin{array}{cc}\text { Breast } & 49.6 \pm 1.4 \\ \text { Cervical } & 50.2 \pm 4.3 \\ \text { Esophageal } & 54.2 \pm 11.3 \\ \text { Head and neck } & 65.0 \pm 5.9 \\ \text { Lung } & 52.1 \pm 8.9\end{array}$

$\begin{array}{cc}49.9 \pm 0.6 & 0.602 \\ 50.7 \pm 3.9 & 0.704 \\ 50.7 \pm 8.6 & 0.776 \\ 65.3 \pm 3.9 & 0.8 \\ 51.4 \pm 10.8 & 0.715\end{array}$

Grade of adverse event**

$\begin{array}{ccccc}0 & 30 & 0 & 25 & 0 \\ 1 & 60 & 0 & 65 & 0 \\ 2 & 0 & 0 & 0 & 0 \\ 3 & 0 & 84 & 0 & 74 \\ 4 & 0 & 6 & 0 & 16\end{array}$

* Average dose was obtained only for patients treated with photon therapy. Prostate cancer was treated using brachytherapy or particle therapy.

**Adverse event mainly: dermatitis for breast cancer; diarrhea, bone marrow suppression for cervical cancer; dysphagia, bone marrow suppression for esophageal cancer; dermatitis, mucositis for head and neck cancer; pneumonitis, bone marrow suppression for lung cancer; dysuria for prostate cancer.

Abbreviations: LGG = Low grade group, HGG = High grade group, RT = radiotherapy, TNM = Tumor Node Metastasis 
controlling procedure of Benjamini and Hochberg [25]. Association between particular alleles of a microsatellite and grade of radiosensitivity was performed using the Cochran-Armitage test for trend [26]

\section{Cell culture conditions}

Normal human skin fibroblast NB1RGB cells were obtained from Riken Cell Bank (Tsukuba, Japan) and maintained in Eagle's minimum essential medium (Nissui, Tokyo, Japan) supplemented with $10 \%$ fetal bovine serum (FBS) and nonessential amino acids under a humidified atmosphere of $5 \% \mathrm{CO}_{2}$ at $37^{\circ} \mathrm{C}$.

\section{siRNA treatment of human fibroblast cultures}

Two different siRNAs (1: 135598, 2: 135597, Applied Biosystems/Ambion, Austin, USA) designed for the human SEMA3A gene were used to treat cells by reverse transfection. Cultured cells were harvested by incubation with $0.05 \%$ trypsin, $0.53 \mathrm{mM}$ EDTA in phosphate-buffered saline (trypsin-EDTA/PBS) for $5 \mathrm{~min}$ at room temperature, followed by inactivation of the trypsin by adding complete culture medium. The number of cells with a diameter of $12 \mu \mathrm{m}$ was measured using the Z1 Coulter Particle Counter (Beckman Coulter, Brea, USA). Transfection complexes were prepared in $266.6 \mu$ l OptiMEM serum free medium by mixing $5.4 \mu \mathrm{L}$ of siPORT NeoFX Transfection Reagent (Applied Biosystems/ Ambion, Austin, USA) for $10 \mathrm{~min}$ prior to adding $2.7 \mu \mathrm{l}$ of $10 \mu \mathrm{M}$ siRNA (Applied Biosystems/Ambion, Austin, USA) for $10 \mathrm{~min}$. The cell suspension containing 27,000 cells in $725.3 \mu \mathrm{l}$ was added to the transfection complexes and the mixture plated onto a $35 \mathrm{~mm}$ plastic dish. Cells were maintained under a humidified atmosphere of $5 \% \mathrm{CO}_{2}$ at $37^{\circ} \mathrm{C}$ for 24 hours. The mock control cells were treated similarly, except the transfection complexes were prepared without siRNA. The transfection medium was then changed to complete culture medium, and cells were maintained for the indicated time.

\section{Western blotting}

The post-transfection complete culture medium was recovered at the indicated time, centrifuged at $12,000 \times$ $\mathrm{g}$ for $5 \mathrm{~min}$ and the supernatant transferred to a microfuge tube and stored at $-30^{\circ} \mathrm{C}$ until use. Fifteen $\mu \mathrm{L}$ aliquots of supernatant were mixed with $5 \mu \mathrm{L}$ of loading dye, incubated at $80^{\circ} \mathrm{C}$ for $10 \mathrm{~min}$ and loaded onto NuPAGE 4-12\% polyacrylamide Bis-Tris gradient gels (Invitrogen, Carlsbad, USA) under denaturing conditions. Proteins in the gels were then transferred onto PVDF membranes by the iBlot Gel Transfer Device (Invitrogen, Carlsbad, USA). The membranes were probed with primary rabbit polyclonal antibody SEMA (H-300) against amino acids 103-402 of the human protein from SEMA3A (Santa Cruz Biotechnology, Santa Cruz, USA). A secondary donkey anti-rabbit IgG conjugated to horseradish peroxidase (GE Healthcare, Amersham Place, UK) was used to detect protein bands using an ECL Advance Western Blotting Detection Kit (GE Healthcare, Little Chalfont, UK).

\section{Radiosensitivity assay of siRNA-treated human skin fibroblast cultures}

Cells cultured for 48 hours following replacement of the siRNA transfection medium, were harvested by incubation with trypsin-EDTA/PBS for $5 \mathrm{~min}$ at room temperature. Trypsin was then inactivated by adding complete culture medium, and the number of cells with a diameter of more than $12 \mu \mathrm{m}$ was counted using a Z1 Coulter Particle Counter. The appropriate number of cells $(1,000$ cells for $0 \mathrm{~Gy}, 1,500$ cells for $1 \mathrm{~Gy}, 3,000$ cells for $2 \mathrm{~Gy}$, 6,000 cells for $3 \mathrm{~Gy}$ and 12,000 cells for $4 \mathrm{~Gy}$ ) were then irradiated at room temperature with $200 \mathrm{kV}$ X-rays (20 $\mathrm{mA})$ with $0.5 \mathrm{~mm}$ aluminum and $0.5 \mathrm{~mm}$ copper filters. Immediately after irradiation, cells were plated onto $100 \mathrm{~mm}$ (0 and $1 \mathrm{~Gy}$ ) or $150 \mathrm{~mm}$ (2-4 Gy) plastic dishes, and cultured under a humidified atmosphere of $5 \% \mathrm{CO}_{2}$ at $37^{\circ} \mathrm{C}$ for 2 weeks. Cells were washed with PBS, then fixed in $100 \%$ methanol for a few minutes at room temperature. After removing the methanol, the cells were dried for 30 minutes and then stained with $3 \%$ Giemsa solution for 2 hours. Colonies consisting of more than 50 cells were scored as survivors. Experiments were performed with triplicate plating of cells. Relative colony survival as a function of irradiated dose was tested using the linear-quadratic model [27].

\section{Results}

\section{Genome-wide association study}

The entire human genome was screened using 23,244 microsatellite markers and one set of the pooled DNA from each group (HGG-1 and LGG-1). This analysis identified 3,052 markers with allele/s that showed significantly different estimated frequency $(P<0.05)$ between the two groups (see figure 1A). These markers were further analyzed in the second round screening with the remaining set of pooled DNA samples from each group (HGG-2 and LGG-2). A total of 101 markers had allele/ $\mathrm{s}$ with significantly different estimated frequency $(P<$ 0.05 ) between the two groups, and had similar peak association patterns in the data from the first and second DNA pools (see figure 1B). The FDR of the markers analyzed in the second round screening was then estimated to correct for the effect of multiple comparisons. After correction for the multiple comparisons performed, 47 autosomal markers had a FDR $<0.05$, and so were significantly associated with radiosensitivity in this study. These markers are summarized in table 2 . 


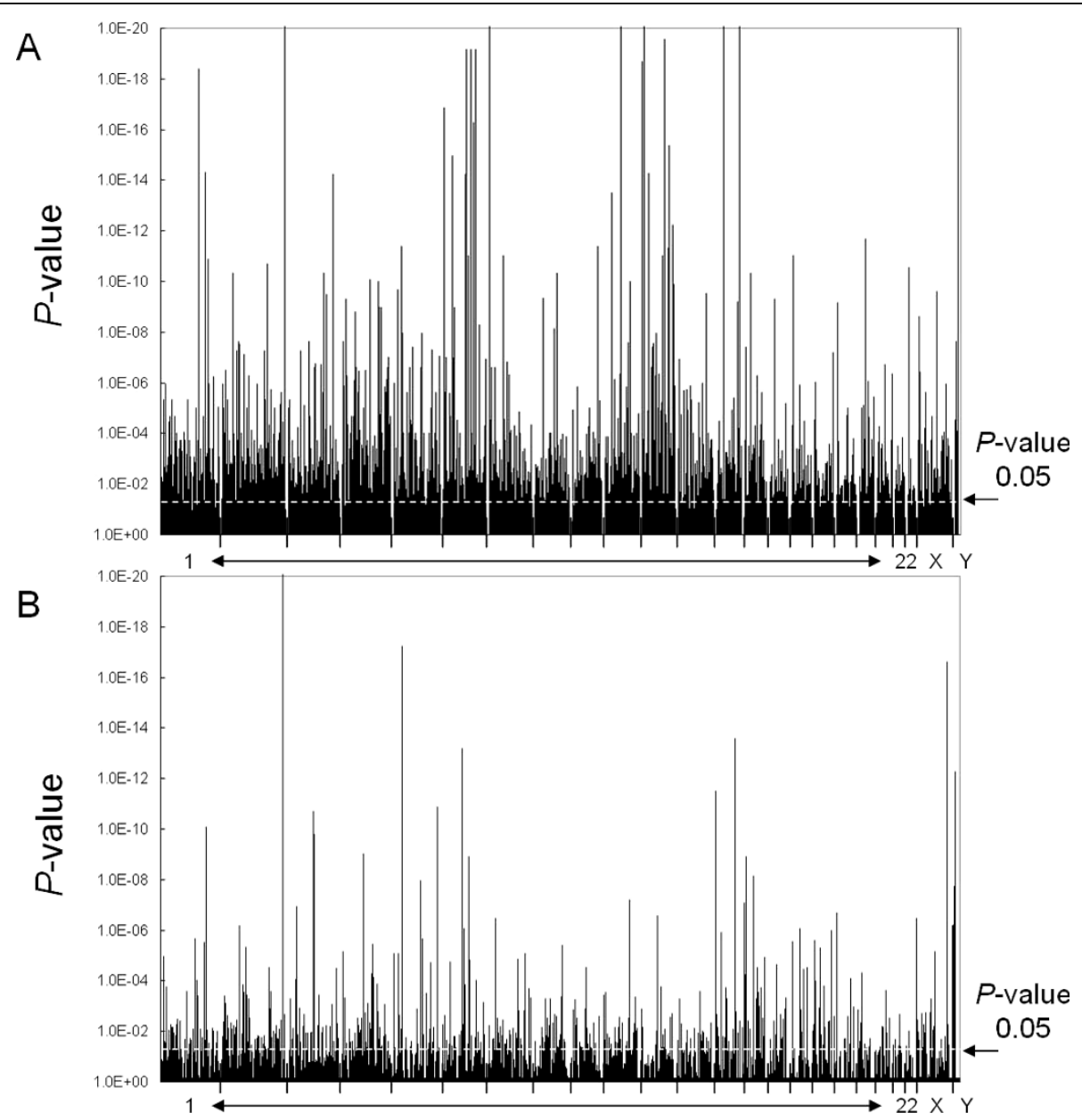

Figure 1 Results of two rounds of screening of microsatellite markers for association with radiosensitivity. (A) Results of the screen of the entire genome using 23,244 microsatellite markers and the HGG-1 and LGG-1 pooled DNAs. (B) Results of screening 3,052 markers of interest identified in the preceding genome scan and using the HGG-2 and LGG-2 pooled DNAs. $P$ values calculated using Fisher's exact test and $2 \times 2$ contingency tables are shown. The level of significance $(P<0.05)$ is shown as a horizontal broken line.

\section{Individual patient typing of selected markers}

The genomic location of the 47 positive markers was determined using the UCSC Genome Browser. Four markers were within $15 \mathrm{~kb}$ upstream of the transcription start site for the nearest gene (table 3). To confirm the associations observed in the pooled DNA analysis, these four markers were individually typed in all 360 patients. The particular alleles of D1S0288i and D7S0338i found to be statistically significantly associated with radiosensitivity in the experiments using pooled DNA, were also found to be so when experiments using individual DNA samples were used (table 3 ). One of the positive markers, D7S0338i, was selected for further study as it had the strongest association with radiosensitivity.

\section{Detailed association analysis of the D7S0338i marker}

Allelic distribution of the marker D7S0338i is represented in additional file 1 . Eleven alleles were identified in D7S0338i, with three major alleles (292 bp, $294 \mathrm{bp}$ and $296 \mathrm{bp}$ ) accounting for more than $90 \%$ of the alleles in the study population (see table 4 and additional file 1 ). Among them, two alleles (292 bp and $296 \mathrm{bp}$ ) had an overall $P$ value $<0.05$. Association analysis revealed the $292 / 292$ genotype was associated with risk reduction (odds ratio: 0.490, 95\% CI: 0.271-0.885), the 294/294 genotype was associated with intermediate risk (odds ratio: 0.794, 95\% CI: 0.321-1.966), and the 296/296 genotype was associated with an increased risk (odds ratio: 2.861, 95\% CI: 1.417-5.774) (see table 5). Interestingly, the heterozygote individuals carrying the risk reducing and risk increasing alleles (292/296) had intermediate risk (odds ratio: 1.152 , 95\% CI: $0.727-1.824)$. This suggests the inter-allele relationship may not behave in the usual dominant-recessive manner. A linear trend was identified between six combinations of alleles for the marker and radiosensitivity $\left(P=7.228 \times 10^{-4}\right)($ see table 5$)$. 
Table 2 List of markers showing positive association with radiosensitivity

\begin{tabular}{|c|c|c|c|c|c|c|c|c|c|}
\hline \multirow[t]{2}{*}{ Number } & \multirow[t]{2}{*}{ Marker } & \multirow[t]{2}{*}{ Chr } & \multicolumn{2}{|c|}{ Position in hg18* } & \multicolumn{2}{|c|}{ Sequence of PCR primers } & \multicolumn{2}{|c|}{$P$ value } & \multirow[t]{2}{*}{ FDR } \\
\hline & & & 5'-end & 3'-end & Forward & Reverse & 1 st & 2nd & \\
\hline 1 & D5S0329i & 5 & 33286356 & 33286817 & GAAAGAATTACACTTTGCCAA & AATTGAGATGTCTAAAGGCATC & $2.549 \mathrm{E}-05$ & $5.916 \mathrm{E}-18$ & 3.897E-15 \\
\hline 2 & D6S0876i & 6 & 82039209 & 82039634 & ACCACAATAAGATATCACCTCAC & CATTACATTCATGCATACACATAC & 0.0263 & $6.518 \mathrm{E}-14$ & 1.717E-11 \\
\hline 3 & D3S0313i & 3 & 104474152 & 104474509 & AACCATCAGATCTTGTTAGAATTA & GTAGTGGTACAGGCCTGTAGT & 2.409E-07 & $2.082 \mathrm{E}-11$ & 3.048E-09 \\
\hline 4 & D1S0494i & 1 & 199551754 & 199551974 & GTGTAAGAGCCAGCTGGAC & TCTTGTITGTGTCTGGTATTAGG & 0.0066 & $8.736 \mathrm{E}-11$ & 1.151E-08 \\
\hline 5 & D3S0923i & 3 & 105397288 & 105397735 & GGTATCATTTATCTGGATCCAC & AATTCTITCAGATGAAAGGAAG & 4.025E-04 & $1.714 \mathrm{E}-10$ & $2.052 \mathrm{E}-08$ \\
\hline 6 & D5S0365i & 5 & 111127178 & 111127405 & ACACAAATAAGCATGCGC & CCAGATTATCCTACCACGC & $1.127 \mathrm{E}-08$ & 1.127E-08 & 9.279E-07 \\
\hline 7 & D14S0444i & 14 & 26355444 & 26355548 & TCATAGCACTTATCACTACCTTAGG & GATGAAGCCAAGGAGGAG & $3.863 \mathrm{E}-08$ & 8.37E-08 & $5.80 \mathrm{E}-06$ \\
\hline 8 & D7S0192i & 7 & 24587185 & 24587633 & ATTACCATTATGGTAGGCTGAATA & GCCAGACATTTGAAATCAGTAT & 0.0025 & 3.53E-07 & 1.95E-05 \\
\hline 9 & D5S0292i & 5 & 117035880 & 117036332 & ACTTATAGGTCAGCAACCATTC & GCAATTAGATGGCATTAAATTA & $2.82 \mathrm{E}-04$ & $2.27 \mathrm{E}-06$ & 8.80E-05 \\
\hline 10 & D175945 & 17 & 9763962 & 9764159 & AACCAATCTGGACTCCCC & CCTGAAGCCTGACCCC & $4.52 \mathrm{E}-04$ & $2.70 \mathrm{E}-06$ & $1.02 \mathrm{E}-04$ \\
\hline 11 & D4S0813i & 4 & 122056656 & 122057077 & TCTTCAGCATTCAGAATATGAT & CAAATTGTCTTTGTTATGTACCTC & $4.98 \mathrm{E}-04$ & $3.66 \mathrm{E}-06$ & 1.27E-04 \\
\hline 12 & D850809i & 8 & 121379855 & 121380093 & AAGTTATTTATACCAAGTGATGGTG & TCCTAGGATCCTAAGATATAAATCTG & 0.0455 & 3.89E-06 & 1.32E-04 \\
\hline 13 & D5S1310i & 5 & 2137543 & 2137692 & AGCCTTCACTCGTGTTCTTAC & AAATAGGAGGACAGAGTAGCAGAG & $4.72 \mathrm{E}-04$ & $8.25 \mathrm{E}-06$ & $2.41 \mathrm{E}-04$ \\
\hline 14 & D7S1017i & 7 & 135196215 & 135196636 & ACTGTTCTCATGGTAGTGAATAAG & СTCTTCCTCGTTTGTAGACAC & 0.0039 & $8.78 \mathrm{E}-06$ & 2.52E-04 \\
\hline 15 & D950704i & 9 & 82887428 & 82887533 & TGCCATGACTGTCTTTCC & TGGAACAAATGATATCAAGAGATAG & 0.006 & $3.02 \mathrm{E}-05$ & $6.22 \mathrm{E}-04$ \\
\hline 16 & D7S0072i & 7 & 147781781 & 147782230 & TTCATGAATCCTCAACTATTAAAG & GCTTACTACCTGGTTAATGAAATA & 0.0081 & $2.11 \mathrm{E}-04$ & 0.0030 \\
\hline 17 & D20S0325i & 20 & 47715303 & 47715449 & GTTATGATCATGTCACTGCAC & CCTTAGGACTTGATGTTTCTTC & 0.0069 & $2.39 \mathrm{E}-04$ & 0.0034 \\
\hline 18 & D10S0385i & 10 & 7092531 & 7092986 & GGATAACTCCAAGATTTCTGAC & GATTAACATGTAAATAGGCAGACT & 0.0143 & $2.90 \mathrm{E}-04$ & 0.0038 \\
\hline 19 & D8S0335i & 8 & 116305649 & 116306128 & TTAATATTGATAACATCTTGCGA & CCTTATGACAAATCTITTCTGAG & 0.0266 & 4.40E-04 & 0.0053 \\
\hline 20 & D350046i & 3 & 6944093 & 6944453 & ATGGCCATGTTATGATGTTAAT & TGACAGAGCTAGACTCTTGTCAG & 0.0247 & $4.98 \mathrm{E}-04$ & 0.0054 \\
\hline 21 & D14S0356i & 14 & 75942526 & 75942991 & TACTCAAATGTCACATTGGTTA & CAGACTAATCAATAACAGAGGACT & 8.30E-04 & $5.00 \mathrm{E}-04$ & 0.0054 \\
\hline 22 & D15S966 & 15 & 96766304 & 96766555 & TGCTGCTCACGAACTTIT & CCTCTTGGGAACTGTGTAGTATT & 0.0142 & 4.87E-04 & 0.0054 \\
\hline 23 & D9S0416i & 9 & 7107471 & 7107725 & AATATTACCTTATTGTTGAGTAAATGC & CCAACAATATAATTTAGGAAGAGC & 0.0187 & 0.0014 & 0.0127 \\
\hline 24 & D1350138i & 13 & 100138248 & 100138637 & AGACTCATCTCCTACCTITCAC & TAAGAATCCATATGTTGCTGAC & 0.0017 & 0.0017 & 0.0147 \\
\hline 25 & D9S0242i & 9 & 8735688 & 8736162 & CGTTGTAATTGAACGAATAAC & CACCTTGTCACAATTACTCAAC & 0.0087 & 0.0019 & 0.0160 \\
\hline 26 & HUMUT6930B & 21 & 39672158 & 39672587 & CGGAGGTTGCAGTGAGTTG & GGGAAGGCTATGGAGGAGA & 0.0007 & 0.0022 & 0.0174 \\
\hline 27 & D8S0912i & 8 & 89632493 & 89632925 & GGATGTCTTGTCTTACATTCTCTAG & CAGGTGTCTACTAAACCATCTGAC & 0.0231 & 0.0023 & 0.0178 \\
\hline 28 & D6S0444i & 6 & 9065374 & 9065718 & AATTAAGAGTGATCTGAGCAGAAG & TCAAATTTGGTGACCTTAACAG & 0.0016 & 0.0023 & 0.0182 \\
\hline 29 & D5S0803i & 5 & 23507111 & 23507556 & TGGTATTAATCTGTTAATGAGGAC & GAATCAACCTAAGTGTACATCAAC & 0.0357 & 0.0024 & 0.0186 \\
\hline 30 & D1850429i & 18 & 487260 & 487643 & CGGATCACCATATAGTGAAAC & GAATTAGAAAGTCACGTTGGTAC & 0.0269 & 0.0026 & 0.0194 \\
\hline 31 & HUMUT544 & 11 & 123087682 & 123087978 & ACTTCAGCCTCGGTGACAG & TGTTCTGCCTCTGTTGTTAC & 0.0453 & 0.0027 & 0.0202 \\
\hline 32 & D4S0317i & 4 & 64967890 & 64968058 & GATACAATTGGTACTGCAAAATAC & TCCTAAGTTCCTAAAGAATCACTC & 0.0000 & 0.0030 & 0.0215 \\
\hline 33 & D8S0674i & 8 & 60955922 & 60956375 & TाTCTAATCCATCTGTCAATAAAG & AGTCACTATGCATAGACCACAC & 0.0004 & 0.0031 & 0.0220 \\
\hline 34 & D7S2422 & 7 & 51105545 & 51105739 & GCTCCACATTCCTTGGGTA & AAGTGAGGGCCTITCAAAC & 0.0131 & 0.0037 & 0.0249 \\
\hline 35 & D10S0463i & 10 & 73857334 & 73857571 & AGAGTAAATCCTCTCCTCATACAAG & TTGCACAGTTCAGAAGCC & 0.0046 & 0.0045 & 0.0288 \\
\hline 36 & D8S0225i & 8 & 30387109 & 30387478 & CAGTTGGAATAAATCAGTGAAC & CTGGCTAACATGGTGAAAC & 0.0077 & 0.0070 & 0.0370 \\
\hline 37 & D1050809i & 10 & 48104477 & 48104600 & GCTAGTGTTGGGAGTCAGC & AGGTGAGCCAGTTTCCAG & 0.0123 & 0.0068 & 0.0370 \\
\hline 38 & D20S0115i & 20 & 36321601 & 36321804 & ATACTGGCACAAACGCATC & TTAGACTCAGCTATGGAAAGTCAG & 0.0013 & 0.0068 & 0.0370 \\
\hline 39 & D12S0456i & 12 & 64866094 & 64866556 & ATTTACCTATGTAACAAACTGCAC & CACAGACTTAATGGATAAGCAG & 0.0042 & 0.0075 & 0.0383 \\
\hline 40 & D4S0132i & 4 & 30434753 & 30434922 & CCAGAAGATAGAAGGAGAATCAC & TCTTGATGGTTGGCTGTC & 0.0300 & 0.0085 & 0.0401 \\
\hline 41 & D7S0338i & 7 & 83663532 & 83663831 & CTTAACAATACTGGCTGATCAATAG & CATTGTCACTACAGCTTTCATTAC & 0.0013 & 0.0088 & 0.0413 \\
\hline 42 & D12S0341i & 12 & 33909083 & 33909516 & TCAAACCTTCATCTTTGTACTTAG & AACTGGCTTCTATCTCACCTAT & 0.0223 & 0.0089 & 0.0416 \\
\hline 43 & D1S0288i & 1 & 33214510 & 33214921 & ATACTGTACTTCATGCCATAAGAC & GAGAAATACGGCTGGTGTA & 0.0000 & 0.0092 & 0.0425 \\
\hline 44 & D1S1215i & 1 & 241929347 & 241929516 & CTGCAGTCACAACTGGTTAAG & TTGATAACAGCATACTTCAACATAG & 0.0027 & 0.0097 & 0.0430 \\
\hline 45 & D12S1657 & 12 & 96183565 & 96183714 & TCCTAAAGATGGTGTGCAT & AAGTTCCAATGTTAGTGAACC & 0.0431 & 0.0100 & 0.0435 \\
\hline 46 & D1650497i & 16 & 59449366 & 59449516 & GTAAATCCAATATCTTGCCTACAG & TTCAGGTTCTCCATGTCAAC & 0.0361 & 0.0104 & 0.0446 \\
\hline 47 & D1050107i & 10 & 119415495 & 119415711 & ACAGGCAATCTGATAGTTTAAGAG & AATTGACTCAAGGTTCTGCAG & 0.0254 & 0.0112 & 0.0469 \\
\hline
\end{tabular}

* hg18: human genome assembly version 18

Abbreviation: $\mathrm{Chr}=$ Chromosome, 
Table 3 Reproducibility of markers located within $15 \mathrm{~kb}$ distance to the nearest transcription start sit

\begin{tabular}{|c|c|c|c|c|c|c|c|c|}
\hline \multirow[t]{2}{*}{ Chr } & \multirow[t]{2}{*}{ Marker } & \multirow[t]{2}{*}{ Repeat Unit } & \multirow[t]{2}{*}{ Nearest gene } & \multirow[t]{2}{*}{ Distance to TS } & \multirow[t]{2}{*}{$2^{\text {nd }}$ screen FDR } & \multicolumn{3}{|c|}{$P$ values } \\
\hline & & & & & & $1^{\text {st }}$ screen & $2^{\text {nd }}$ screen & Overall \\
\hline 1 & D1S0288i & GAA & $\begin{array}{c}\text { IBRDC3 } \\
\text { (IBR domain } \\
\text { containing 3) }\end{array}$ & 12196 bp & $\underline{0.043}$ & $\underline{0.019}$ & $\underline{0.041}$ & $\underline{0.001}$ \\
\hline 5 & D5S0365i & TG & $\begin{array}{c}\text { C5orf13 } \\
\text { (Protein p311) }\end{array}$ & $6571 \mathrm{bp}$ & $\underline{9.28 \mathrm{E}-07}$ & 0.031 & 0.639 & 0.054 \\
\hline 7 & D7S0338i & GA & $\begin{array}{c}\text { SEMA3A } \\
\text { (Semaphorin-3A) }\end{array}$ & $1453 \mathrm{bp}$ & $\underline{0.041}$ & 0.012 & $2.70 \mathrm{E}-04$ & $1.24 \mathrm{E}-05$ \\
\hline 12 & D12S0456i & $\mathrm{TG}$ & $\begin{array}{c}\text { IRAK3 } \\
\text { (Interleukin-1 receptor- } \\
\text { associated kinase 3) }\end{array}$ & 2796 bp & $\underline{0.038}$ & 0.018 & 0.194 & $\underline{0.008}$ \\
\hline
\end{tabular}

Abbreviation: $\mathrm{Chr}=$ chromosome, $\mathrm{TS}=$ transcription start site, FDR = false discovery rate

Impact on cellular radiosensitivity of the D7S0338i associated gene SEMA3A

The D7S0338i marker is 1500 bp upstream of the transcription start site of the SEMA3A gene (table 3). The linkage disequilibrium block around this marker did not extend to neighbouring genes (see additional file 2). To assess possible functional impacts of the SEMA3A gene on cellular radiosensitivity (see additional file 3 ), a model system using in vitro irradiation of cultured fibroblasts derived from human skin was employed. Specific SEMA3A siRNA treatment of these cells reduced expression of the $S E M A 3 A$ gene in normal human skin fibroblasts (see additional file 4). When these cells were irradiated with X-rays (200 keV), the colony survival assay of the irradiated cells showed enhancement of cellular radiation resistance in the SEMA3A siRNA-treated cells (see figure 2).

\section{Discussion}

A human genome-wide microsatellite association study was performed in cancer patients who showed radiation-induced adverse reactions. After correction for multiple comparisons, this study identified 47 autosomal markers with a FDR $<0.05$. One of these markers is within the proximal promoter region of the $S E M A 3 A$ gene on chromosome 7. Knockdown of SEMA3A expression in a normal human skin fibroblast culture caused a significant change in the radiosensitivity of these cells.

The SEMA3A gene has not been previously described as having a role in radiosensitivity. $S E M A 3 A$ encodes a secreted protein (semaphorin-3A), which is involved in a wide range of functional processes including regulation of axon guidance, cell survival, motility, immune responses and angiogenesis [28-49] (see additional file 3 ). This diversity of these roles provides many possible mechanisms for its involvement in radiosensitivity. Semaphorin-3A is also a competitor of the angiogenic growth factor coded for by the VEGF gene, as both bind to the same transmembrane receptor $[29,31,46]$. As VEGF expression is directly correlated with

Table 4 Allelic association analysis for the D7S0338i marker using Fisher's exact test

\begin{tabular}{|c|c|c|c|c|c|c|c|c|c|}
\hline \multirow[b]{2}{*}{ Allele (bp) } & \multicolumn{3}{|c|}{$1^{\text {st }}$ screen } & \multicolumn{3}{|c|}{$2^{\text {nd }}$ screen } & \multicolumn{3}{|c|}{ Overall results } \\
\hline & LGG n(\%) & HGG n(\%) & $P$ value & LGG $n(\%)$ & HGG $n(\%)$ & $P$ value & LGG n(\%) & HGG n(\%) & $P$ value \\
\hline 278 & $0(0.0)$ & $1(0.6)$ & 1.000 & $1(0.6)$ & $1(0.6)$ & 1.000 & $1(0.3)$ & $2(0.6)$ & 1.000 \\
\hline 282 & $0(0.0)$ & $0(0.0)$ & 1.000 & $1(0.6)$ & $1(0.6)$ & 1.000 & $1(0.3)$ & $1(0.3)$ & 1.000 \\
\hline 284 & $1(0.6)$ & $0(0.0)$ & 0.494 & $0(0.0)$ & $0(0.0)$ & 1.000 & $1(0.3)$ & $0(0.0)$ & 0.496 \\
\hline 288 & $1(0.6)$ & $1(0.6)$ & 1.000 & $0(0.0)$ & $1(0.6)$ & 1.000 & $1(0.3)$ & $2(0.6)$ & 1.000 \\
\hline 290 & $0(0.0)$ & $1(0.6)$ & 1.000 & $0(0.0)$ & $0(0.0)$ & 1.000 & $0(0.0)$ & $1(0.3)$ & 1.000 \\
\hline 292 & $88(50.0)$ & $68(37.8)$ & 0.025 & 79 (44.4) & $58(32.2)$ & 0.022 & 167 (47.2) & 126 (35.0) & $\underline{0.001}$ \\
\hline 294 & $37(21.0)$ & $39(21.7)$ & 0.898 & $45(25.3)$ & 37 (20.6) & 0.315 & $82(23.2)$ & $76(21.1)$ & 0.529 \\
\hline 296 & $44(25.0)$ & $68(37.8)$ & 0.012 & $47(26.4)$ & $81(45.0)$ & $2.70 \mathrm{E}-04$ & $91(25.7)$ & 149 (41.4) & 1.24E-05 \\
\hline 298 & $4(2.3)$ & $1(0.6)$ & 0.211 & $4(2.2)$ & $1(0.6)$ & 0.214 & $8(2.3)$ & $2(0.6)$ & 0.062 \\
\hline 300 & $0(0.0)$ & $1(0.6)$ & 1.000 & $0(0.0)$ & $0(0.0)$ & 1.000 & $0(0.0)$ & $1(0.3)$ & 1.000 \\
\hline 302 & $1(0.6)$ & $0(0.0)$ & 0.494 & $1(0.6)$ & $0(0.0)$ & 0.497 & $2(0.6)$ & $0(0.0)$ & 0.245 \\
\hline
\end{tabular}


Table 5 Genotype association analysis of D7S0338i marker

\begin{tabular}{ccccccc}
\hline Number & Genotype & LGG & HGG & $\begin{array}{c}\boldsymbol{P} \\
\text { value }\end{array}$ & $\begin{array}{c}\text { Odds } \\
\text { ratio }\end{array}$ & $\mathbf{9 5 \% ~ C l}$ \\
\cline { 3 - 5 } & & $\mathbf{n ~ ( \% )}$ & $\mathbf{n ~ ( \% )}$ & & & \\
\hline $1^{*}$ & $292 / 292$ & 36 & 20 & 0.017 & 0.490 & $0.271-$ \\
& & $(20.3)$ & $(11.1)$ & & & 0.885 \\
$2^{*}$ & $292 / 294$ & 41 & 29 & 0.093 & 0.637 & $0.375-$ \\
& & $(23.2)$ & $(16.1)$ & & & 1.081 \\
$3^{*}$ & $294 / 294$ & $11(6.2)$ & $9(5.0)$ & 0.788 & 0.794 & $0.321-$ \\
& & & & & & 1.966 \\
$4^{*}$ & $292 / 296$ & 48 & 54 & 0.547 & 1.152 & $0.727-$ \\
& & $(27.1)$ & $(30.0)$ & & & 1.824 \\
$5^{*}$ & $294 / 296$ & $17(9.6)$ & 28 & 0.090 & 1.734 & $0.912-$ \\
& & & $(15.6)$ & & & 3.295 \\
$6^{*}$ & $296 / 296$ & $12(6.8)$ & 31 & 0.002 & 2.861 & $1.417-$ \\
& & \multicolumn{7}{c}{$(17.2)$} & & & 5.774 \\
7 & Others & $12(6.8)$ & $9(5.0)$ & 0.624 & 0.724 & $0.297-$ \\
& & & & & & 1.763 \\
\hline
\end{tabular}

${ }^{*}$ Cochran-Armitage trend test: $P=7.228 \times 10^{-4}$

radiosensitivity [50], its competitor, semaphorin-3A, may also be associated with radiosensitivity.

The potential role of the D7S0338i marker in radiosensitivity is interesting. The microsatellite is located $1500 \mathrm{bp}$ upstream from the transcription start site of SEMA3A, and is a GA dinucleotide repeat (see additional file 5). Two other polymorphic repetitive

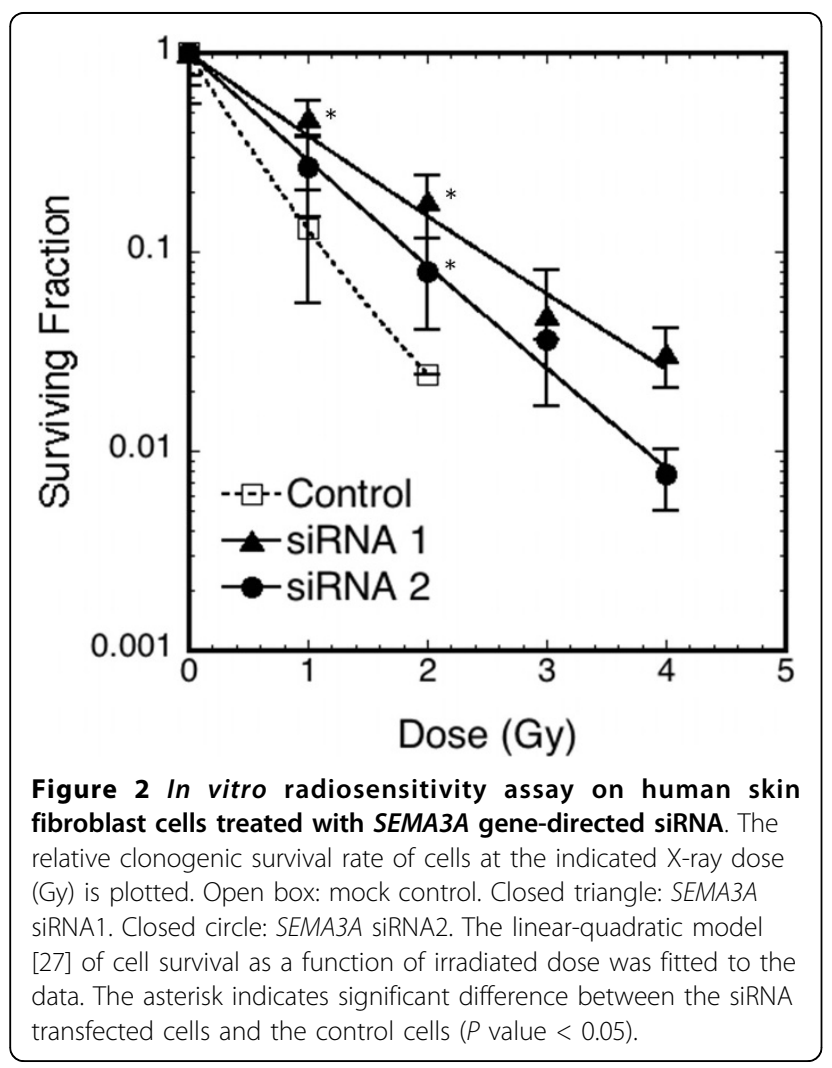

sequences also occur between the D7S0338i marker and the SEMA3A transcription start site (additional file 6). These three repetitive sequences are in a low nucleosome occupancy region (data not shown). Since nucleosomes play a major role in generating the higher order structure of chromatin that regulates gene expression [51], these sequences may affect the activity of the $S E M A 3 A$ promoter. A study into the activity of the $S E M A 3 A$ promoter may provide information on the functional impacts of the D7S0338i marker polymorphism, especially mechanisms underlying the phenotypes associated with various alleles (table 5).

A major limitation of association studies on rare phenotypes such as the severe (equal to or greater than grade 3 ), acute, adverse reactions induced by radiotherapy, is the ability to enroll sufficient numbers of patients to provide adequate statistical power $[7,52]$. The reproducibility of any association identified must also be replicated [53], further increasing the required patient number. Hence in this study, cancer patients were selected with differing severe, acute, adverse reaction endpoints and various cancer types. Identical numbers of control patients were selected who did not develop severe, adverse reactions on any endpoint. The clinical characteristics and therapeutic protocols used in the control and subject patients were also similar (table 1). While this suggests inherent or genetic differences between patients are the cause of the variations in severity in patient reactions, the involvement of $S E M A 3 A$ requires further validation using large numbers of patients with a unique cancer type.

A possible implication for this study's finding that semaphorin-3A may be involved in radiosensitivity, is the identification of a potential new agent for the treatment of radiotherapy-induced damage. SM-216289 (xanthofulvin) was originally isolated from the fermentation broth of a fungal strain, Penicillium sp. SPF-3059, and is a natural inhibitor of Semaphorin-3A [54]. SM216289 abolished the growth cone collapse of dorsal root ganglion neurons that was induced by Semaphorin$3 \mathrm{~A}$ in vitro and in vivo, possibly through direct interference of the receptor-ligand association [54]. Local administration of SM-216289 in the adult rat model of spinal cord injury, substantially enhanced functional recovery of injured axons, with decreases in apoptotic cell number and marked enhancement of angiogenesis [55]. Therefore, locally administered SM-216289 may aid functional recovery in radiotherapy-induced injury.

Increasingly, phenotypic differences have been shown to be caused by diverse genetic variations. While SNP and repetitive DNA polymorphisms have been shown to be disease-associated, other disease-associated changes include copy number variation [56] and transgenerational epigenetic modification of the genome [57]. Thus, diagnostic testing should be considered to identify highly 
radiosensitive cancer patients through the detection of genetic variants in individual patients. The rapidly developing next-generation genome sequencing technology [58] may be the most suitable one for this purpose.

\section{Conclusions}

A total of 47 putative markers for individual radiosensitivity were identified using a genome-wide screen based on microsatellite markers. One of these markers is in the proximal promoter region of SEMA3A, with knockdown of this gene using siRNA supporting its potential role in radiosensitivity.

\section{Additional material}

Additional file 1: Allele frequencies for the D7S0338i marker. (A)

First screening samples. (B) Second screening samples. (C) Overall results. The number of patients with the indicated allele size is plotted. Reproducible allele frequency differences were observed between the groups. White bar: LGG. Black bar: HGG. Significant differences $(P<0.05$ by Fisher's exact test based on $2 \times 2$ contingency tables) are indicated by the vertical lines.

Additional file 2: Linkage disequilibrium map around the D7S0338i marker. Diagram showing the region of linkage disequilibrium ( $\left.D^{\prime}\right)$ surrounding the SEMA3A gene and neighbouring genes. An increase in the degree of linkage disequilibrium between the SEMA3A gene and its neighbours is represented by an increase in the intensity of red color. Thus, the D750338i marker is in the linkage disequilibrium block that spans the transcriptional regulatory region of the SEMA3A gene. The D data was calculated from JPT and CHB HapMap data. Positions are NCB build 36 coordinates. Gene region and direction of transcription are indicated by an arrow.

Additional file 3: References on semaphorin-3A functions

Additional file 4: Reduction in the amount of semaphorin-3A protein following siRNA treatment. The amount of semaphorin-3A in the culture medium of cells treated by the siRNA was quantified by Western blotting. The protein amounts relative to that of mock control cells are plotted.

Additional file 5: Sequence of the D7S0338i marker. This marker is the GA dinucleotide repeat sequence indicated by the red color. The primer sequences for PCR amplification are indicated by the arrows.

Additional file 6: Location of the D7S0338i marker in the promoter region of the SEMA3A gene. The GA dinucleotide repeat sequence is indicated by an open box. Two other polymorphic repetitive sequences (closed box) exist in the region between the D750338i marker and the transcription start site $(+1)$.

\section{Acknowledgements}

The authors thank the cancer patients for participating in this study. The authors also thank Ms. Masayo Terada for assistance with manuscript preparation. YM thanks Mrs Katsuko Noshiro of NIRS and Ms Erika Matsushita of TU for technical assistance.

\section{Author details}

${ }^{1}$ RadGenomics Project, Research Center for Charged Particle Therapy, National Institute of Radiological Sciences, Chiba, Japan. ${ }^{2}$ Department of Molecular Life Science and Molecular Medicine, Tokai University School of Medicine, Kanagawa, Japan.

\section{Authors' contributions}

YM participated in study conception and design, conducted experiments and statistical analyses, participated in data interpretation, and drafted the manuscript. TS conducted experiments and statistical analysis. Al conducted statistical analyses and participated in data interpretation. $\mathrm{HH}, \mathrm{AO}$ and $\mathrm{HI}$ conducted statistical analyses, participated in data interpretation, and revised the article critically for important intellectual content. MI and TI participated in study conception and design, conducted statistical analyses, participated in data interpretation, and revised the article critically for important intellectual content. All authors read and approved the final manuscript

\section{Competing interests}

The authors declare that they have no competing interests.

Received: 6 December 2009 Accepted: 11 August 2010

Published: 11 August 2010

\section{References}

1. Bentzen SM, Overgaard J: Patient-to-patient variability in the expression of radiation-induced normal tissue injury. Semin Radiat Oncol 1994, 4:68-80.

2. Iwakawa M, Noda S, Yamada S, Yamamoto N, Miyazawa Y, Yamazaki H, Kawakami Y, Matsui Y, Tsujii H, Mizoe J, Oda E, Fukunaga Y, Imai T: Analysis of non-genetic risk factors for adverse skin reactions to radiotherapy among 284 breast cancer patients. Breast Cancer 2006, 13:300-307.

3. Andreassen CN, Alsner J, Overgaard J: Does variability in normal tissue reactions after radiotherapy have a genetic basis - where and how to look for it? Radiother Oncol 2002, 64:131-140.

4. Fernet $\mathrm{M}$, Hall J: Genetic biomarkers of therapeutic radiation sensitivity. DNA Repair 2004, 3:1237-1243.

5. Gatti RA: The inherited basis of human radiosensitivity. Acta Oncol 2001, 40:702-711.

6. Barnett GC, West CM, Dunning AM, Elliott RM, Coles CE, Pharoah PD, Burnet NG: Normal tissue reactions to radiotherapy: towards tailoring treatment dose by genotype. Nat Rev Cancer 2009, 9:134-142.

7. Andreassen CN, Alsner J: Genetic variants and normal tissue toxicity after radiotherapy: a systematic review. Radiother Oncol 2009, 92:299-309.

8. Iwakawa M, Noda S, Ohta T, Ohira C, Lee R, Goto M, Wakabayashi M, Matsui $Y$, Harada $Y$, Imai T: Different radiation susceptibility among five strains of mice detected by a skin reaction. J Radiat Res 2003, 44:7-13.

9. Ohta T, Iwakawa M, Oohira C, Noda S, Minfu Y, Goto M, Tanaka H, Harada Y, Imai T: Fractionated irradiation augments inter-strain variation of skin reactions among three strains of mice. J Radiat Res 2004, 45:515-519.

10. Iwakawa M, Noda S, Ohta T, Tanaka H, Tsuji A, Ishikawa A, Imai T: Strain dependent differences in a histological study of CD44 and collagen fibers with expression analysis of inflammatory response-related genes in irradiated murine lung. J Radiat Res 2004, 45:423-433.

11. Noda S, Iwakawa M, Ohta T, Iwata M, Yang M, Goto M, Tanaka H, Harada Y, Imai T: Inter-strain variance in late phase of erythematous reaction or leg contracture after local irradiation among three strains of mice. Cancer Detect Prev 2005, 29:376-382

12. Ishikawa K, Koyama-Saegusa K, Otsuka Y, Ishikawa A, Kawai S, Yasuda K, Suga T, Michikawa Y, Suzuki M, Iwakawa M, Imai T: Gene expression profile changes correlating with radioresistance in human cell lines. Int I Radiat Oncol Biol Phys 2006, 65:234-245.

13. Ban S, Ishikawa K, Kawai S, Koyama-Saegusa K, Ishikawa A, Shimada Y, Inazawa J, Imai T: Potential in a single cancer cell to produce heterogeneous morphology, radiosensitivity and gene expression. $J$ Radiat Res 2005, 46:43-50.

14. Tsuji AB, Sudo H, Sugyo A, Otsuki M, Miyagishi M, Taira K, Imai T, Harada $\mathrm{YN}$ : A fast, simple method for screening radiation susceptibility genes by RNA interference. Biochem Biophys Res Commun 2005, 333:1370-1377.

15. Suga T, Ishikawa A, Kohda M, Otsuka Y, Yamada S, Yamamoto N, Shibamoto Y, Ogawa Y, Nomura K, Sho K, Omura M, Sekiguchi K, Kikuchi Y, Michikawa Y, Noda S, Sagara M, Ohashi J, Yoshinaga S, Mizoe J, Tsujii H, Iwakawa M, Imai T: Haplotype-based analysis of genes associated with risk of adverse skin reactions after radiotherapy in breast cancer patients. Int J Radiat Oncol Biol Phys 2007, 69:685-693.

16. Michikawa Y, Fujimoto K, Kinoshita K, Kawai S, Sugahara K, Suga T, Otsuka Y, Fujiwara K, Iwakawa M, Imai T: Reliable and fast allele-specific extension of 3'-LNA modified oligonucleotides covalently immobilized on a plastic base, combined with biotin-dUTP mediated optical detection. Anal Sci 2006, 22:1537-1545. 
17. Michikawa Y, Suga T, Ohtsuka Y, Matsumoto I, Ishikawa A, Ishikawa K, Iwakawa M, Imai T: Visible genotype sensor array. Sensors 2008, 8:2722-2735.

18. Michikawa $Y$, Suga T, Ishikawa A, Ohtsuka Y, Iwakawa M, Imai T: Visible haplotype-tag SNP typing array device for human radiation sensitivityassociated genes. Oligonucleotide Array Sequence Analysis New York: Nova PublishersMoretti MK, Rizzo LJ 2008, 3-14.

19. Michikawa $Y$, Sugahara $K$, Suga T, Ohtsuka Y, Ishikawa K, Ishikawa A, Shiomi N, Shiomi T, Iwakawa M, Imai T: In-gel multiple displacement amplification of long DNA fragments diluted to the single molecule level. Anal Biochem 2008, 383:151-158.

20. Payseur BA, Jing PA: Genomewide comparison of population structure at STRPs and nearby SNPs in humans. Mol Biol Evol 2009, 26:1369-1377.

21. Tamiya G, Shinya M, Imanishi T, Ikuta T, Makino S, Okamoto K, Furugaki K, Matsumoto T, Mano S, Ando S, Nozaki Y, Yukawa W, Nakashige R, Yamaguchi D, Ishibashi H, Yonekura M, Nakami Y, Takayama S, Endo T, Saruwatari T, Yagura M, Yoshikawa Y, Fujimoto K, Oka A, Chiku S, Linsen SE, Giphart MJ, Kulski JK, Fukazawa T, Hashimoto H, Kimura M, Hoshina Y, Suzuki Y, Hotta T, Mochida J, Minezaki T, Komai K, Shiozawa S, Taniguchi A, Yamanaka H, Kamatani N, Gojobori T, Bahram S, Inoko H: Whole genome association study of rheumatoid arthritis using 27039 microsatellites. Hum Mol Genet 2005, 14:2305-2321.

22. Kawashima M, Tamiya G, Oka A, Hohjoh H, Juji T, Ebisawa T, Honda Y, Inoko H, Tokunaga K: Genomewide Association Analysis of Human Narcolepsy and a New Resistance Gene. Am J Hum Genet 2006, 79:252-263.

23. Meguro A, Ota M, Katsuyama Y, Oka A, Ohno S, Inoko H, Mizuki N: Association of the toll-like receptor 4 gene polymorphisms with Behçet's disease. Ann Rheum Dis 2008, 67:725-727.

24. Collins HE, Li H, Inda SE, Anderson J, Laiho K, Tuomilehto J, Seldin MF: A simple and accurate method for determination of microsatellite total allele content differences between DNA pools. Hum Genet 2000, 106:218-226.

25. Benjamini $Y$, Hochberg $Y$ : Controlling the false discovery rate: a practical and powerful approach to multiple testing. J R Stat Soc Series B 1995, 57:289-300.

26. Armitage $P$ : Tests for linear trends in proportions and frequencies. Biometrics 1955, 11:375-386.

27. Tucker SL: Tests for the fit of the linear-quadratic model to radiation isoeffect data. Int J Radiat Oncol Biol Phys 1984, 10:1933-1939.

28. Vacca A, Scavelli C, Serini G, Di Pietro G, Cirulli T, Merchionne F, Ribatti D, Bussolino F, Guidolin D, Piaggio G, Bacigalupo A, Dammacco F: Loss of inhibitory semaphorin 3A (SEMA3A) autocrine loops in bone marrow endothelial cells of patients with multiple myeloma. Blood 2006, 108:1661-1667.

29. Narazaki M, Segarra M, Tosato G: Sulfated polysaccharides identified as inducers of neuropilin-1 internalization and functional inhibition of VEGF165 and semaphorin3A. Blood 2008, 111:4126-4136.

30. Guttmann-Raviv N, Shraga-Heled N, Varshavsky A, Guimaraes-Sternberg C, Kessler O, Neufeld G: Semaphorin-3A and semaphorin-3F work together to repel endothelial cells and to inhibit their survival by induction of apoptosis. J Biol Chem 2007, 282:26294-26305.

31. Serini G, Valdembri D, Zanivan S, Morterra G, Burkhardt C, Caccavari F, Zammataro L, Primo L, Tamagnone L, Logan M, Tessier-Lavigne M, Taniguchi M, Püschel AW, Bussolino F: Class 3 semaphorins control vascular morphogenesis by inhibiting integrin function. Nature 2003, 424:391-397.

32. Barresi V, Vitarelli E, Cerasoli S: Semaphorin3A immunohistochemical expression in human meningiomas: correlation with the microvessel density. Virchows Arch 2009, 454:563-571.

33. Moretti S, Procopio A, Lazzarini R, Rippo MR, Testa R, Marra M, Tamagnone L, Catalano A: Semaphorin3A signaling controls Fas (CD95)mediated apoptosis by promoting Fas translocation into lipid rafts. Blood 2008, 111:2290-2299.

34. Schmidt EF, Strittmatter SM: The CRMP family of proteins and their role in Sema3A signaling. Adv Exp Med Biol 2007, 600:1-11.

35. Tannemaat MR, Korecka J, Ehlert EM, Mason MR, van Duinen SG, Boer GJ, Malessy MJ, Verhaagen J: Human neuroma contains increased levels of semaphorin $3 \mathrm{~A}$, which surrounds nerve fibers and reduces neurite extension in vitro. J Neurosci 2007, 27:14260-14264.
36. Herman JG, Meadows GG: Increased class 3 semaphorin expression modulates the invasive and adhesive properties of prostate cancer cells. Int J Oncol 2007, 30:1231-1238.

37. Kurschat $P$, Bielenberg $D$, Rossignol-Tallandier M, Stahl A, Klagsbrun M: Neuron restrictive silencer factor NRSF/REST is a transcriptional repressor of neuropilin-1 and diminishes the ability of semaphorin $3 \mathrm{~A}$ to inhibit keratinocyte migration. J Biol Chem 2006, 281:2721-2729.

38. Lepelletier Y, Smaniotto S, Hadj-Slimane R, Villa-Verde DM, Nogueira AC, Dardenne M, Hermine O, Savino W: Control of human thymocyte migration by neuropilin-1/semaphorin-3A-mediated interactions. Proc Natl Acad Sci USA 2007, 104:5545-5550.

39. Bachelder RE, Lipscomb EA, Lin X, Wendt MA, Chadborn NH, Eickholt BJ, Mercurio AM: Competing autocrine pathways involving alternative neuropilin-1 ligands regulate chemotaxis of carcinoma cells. Cancer Res 2003, 63:5230-5233.

40. Ko JA, Morishige N, Yanai R, Nishida T: Up-regulation of semaphorin $3 \mathrm{~A}$ in human corneal fibroblasts by epidermal growth factor released from cocultured human corneal epithelial cells. Biochem Biophys Res Commun 2008, 377:104-108

41. Kashiwagi $H$, Shiraga M, Kato H, Kamae T, Yamamoto N, Tadokoro S, Kurata $Y$, Tomiyama $Y$, Kanakura $Y$ : Negative regulation of platelet function by a secreted cell repulsive protein, semaphorin 3A. Blood 2005, 106:913-921.

42. Lepelletier Y, Moura IC, Hadj-Slimane R, Renand A, Fiorentino S, Baude C, Shirvan A, Barzilai A, Hermine O: Immunosuppressive role of semaphorin$3 \mathrm{~A}$ on $\mathrm{T}$ cell proliferation is mediated by inhibition of actin cytoskeleton reorganization. Eur J Immunol 2006, 36:1782-1793.

43. Marzioni D, Tamagnone L, Capparuccia L, Marchini C, Amici A, Todros T, Bischof $P$, Neidhart S, Grenningloh G, Castellucci M: Restricted innervation of uterus and placenta during pregnancy: evidence for a role of the repelling signal semaphorin 3A. Dev Dyn 2004, 231:839-848.

44. Eastwood SL, Law AJ, Everall IP, Harrison PJ: The axonal chemorepellant semaphorin $3 \mathrm{~A}$ is increased in the cerebellum in schizophrenia and may contribute to its synaptic pathology. Mol Psychiatry 2003, 8:148-155.

45. Potiron VA, Roche J, Drabkin HA: Semaphorins and their receptors in lung cancer. Cancer Lett 2009, 273:1-14.

46. Catalano A, Caprari P, Rodilossi S, Betta P, Castellucci M, Casazza A, Tamagnone $L$, Procopio A: Cross-talk between vascular endothelial growth factor and semaphorin-3A pathway in the regulation of normal and malignant mesothelial cell proliferation. FASEB J 2004, 18:358-363.

47. Rieger J, Wick W, Weller M: Human malignant glioma cells express semaphorins and their receptors, neuropilins and plexins. Glia 2003, 42:379-389.

48. Müller MW, Giese NA, Swiercz JM, Ceyhan GO, Esposito I, Hinz U, Büchler P, Giese T, Büchler MW, Offermanns $\mathrm{S}$, Friess $\mathrm{H}$ : Association of axon guidance factor semaphorin $3 \mathrm{~A}$ with poor outcome in pancreatic cancer. Int J Cancer 2007, 121:2421-2433.

49. Kigel B, Varshavsky A, Kessler O, Neufeld G: Successful inhibition of tumor development by specific class-3 semaphorins is associated with expression of appropriate semaphorin receptors by tumor cells. PLoS One 2008, 3:e3287.

50. Brieger J, Kattwinkel J, Berres M, Gosepath J, Mann WJ: Impact of vascular endothelial growth factor release on radiation resistance. Oncol Rep 2007, 18:1597-1601.

51. Horowitz RA, Agard DA, Sedat JW, Woodcock C: The three-dimensional architecture of chromatin in situ: electron tomography reveals fibers composed of a continuously variable zig-zag nucleosomal ribbon. J Cell Biol 1994, 125:1-10.

52. Spencer CC, Su Z, Donnelly P, Marchini J: Designing genome-wide association studies: sample size, power, imputation, and the choice of genotyping chip. PLoS Genet 2009, 5:e1000477.

53. NCl-NHGRI working group on replication in association studies: Replicating genotype-phenotype associations. Nature 2007, 447:655-660.

54. Kikuchi K, Kishino A, Konishi O, Kumagai K, Hosotani N, Saji I, Nakayama C, Kimura T: In vitro and in vivo characterization of a novel semaphorin $3 \mathrm{~A}$ inhibitor, SM-216289 or xanthofulvin. J Biol Chem 2003, 278:42985-42991.

55. Kaneko S, Iwanami A, Nakamura M, Kishino A, Kikuchi K, Shibata S, Okano HJ, Ikegami T, Moriya A, Konishi O, Nakayama C, Kumagai K, Kimura T, Sato Y, Goshima Y, Taniguchi M, Ito M, He Z, Toyama Y, Okano H: $A$ selective Sema3A inhibitor enhances regenerative responses and 
functional recovery of the injured spinal cord. Nat Med 2006,

12:1380-1389.

56. Diskin SJ, Hou C, Glessner JT, Attiyeh EF, Laudenslager M, Bosse K, Cole K, Mossé YP, Wood A, Lynch JE, Pecor K, Diamond M, Winter C, Wang K Kim C, Geiger EA, McGrady PW, Blakemore Al, London WB, Shaikh TH, Bradfield J, Grant SF, Li H, Devoto M, Rappaport ER, Hakonarson H, Maris JM: Copy number variation at 1q21.1 associated with neuroblastoma. Nature 2009, 459:987-991.

57. Johannes F, Porcher E, Teixeira FK, Saliba-Colombani V, Simon M, Agier N, Bulski A, Albuisson J, Heredia F, Audigier P, Bouchez D, Dillmann C, Guerche P, Hospital F, Colot V: Assessing the impact of transgenerational epigenetic variation on complex traits. PLoS Genet 2009, 5:e1000530.

58. Ansorge WJ: Next-generation DNA sequencing techniques. Nat Biotechnol 2009, 25:195-203.

\section{Pre-publication history}

The pre-publication history for this paper can be accessed here: http://www.biomedcentral.com/1471-2350/11/123/prepub

doi:10.1186/1471-2350-11-123

Cite this article as: Michikawa et al:: Genome wide screen identifies microsatellite markers associated with acute adverse effects following radiotherapy in cancer patients. BMC Medical Genetics 2010 11:123.

\section{Submit your next manuscript to BioMed Central} and take full advantage of:

- Convenient online submission

- Thorough peer review

- No space constraints or color figure charges

- Immediate publication on acceptance

- Inclusion in PubMed, CAS, Scopus and Google Scholar

- Research which is freely available for redistribution

Submit your manuscript at www.biomedcentral.com/submit 